\title{
Roles of heat shock factor 1 in isoproterenol-induced myocardial fibrosis in mice
}

\author{
YONG XIE ${ }^{1}$, LIHUA ZHANG ${ }^{1}$, BIN $\mathrm{ZHANG}^{2}$ and $\mathrm{LI} \mathrm{FANG}^{3}$ \\ ${ }^{1}$ Department of General Medicine, Chenzhou No. 1 People's Hospital, Chenzhou, Hunan 423000; \\ ${ }^{2}$ Department of Histoembryology, Xiangya School of Medicine, Central South University, Changsha, Hunan 410078; \\ ${ }^{3}$ Department of Internal Cardiology, Changsha No. 1 People's Hospital, Changsha, Hunan 410078, P.R. China
}

Received July 28, 2014; Accepted May 6, 2015

DOI: $10.3892 / \mathrm{mmr} .2015 .4157$

\begin{abstract}
Although it is well known that isoproterenol (ISO) causes myocardial hypertrophy and myocardial fibrosis in rats, it has remained elusive whether heat shock factor 1 (HSF1) has a role in this process. The present study aimed to investigate the possible roles of HSF1 in ISO-induced fibrosis in mice. It was found that after administration of ISO in Kunming and HSF1-/+ mice, there was a large number of fibers deposited around blood vessels and among cardiocytes, accompanied with an obvious increase in the protein expressions of type I or III collagen and heat shock protein 47 (HSP47), as indicated by western blot analysis. After intervention with insulin-like growth factor 1 (IGF-1), myocardial fibrosis was significantly attenuated, with a paralleled decrease in the expression of collagen and HSP47 in the mice. However, in HSF1-/- mice, fiber hyperplasy was not observed after injection of ISO, and the levels of type I or III collagen and HSP47 were not significantly increased at the protein and mRNA level. Furthermore, it was demonstrated that after subcutaneous injection of ISO into the back of Kunming and HSF1-/+ mice, large amounts of HSF1 protein were localized to the nucleus, and there was an increase in phosphorylated HSF1 as indicated by western blot and immunohistochemical analysis, respectively. Intervention with IGF-1 inhibited HSF1 activation mediated by ISO. These results suggested that HSF1 is required for myocardial fibrosis in ISO-treated mice, and the underlying molecular mechanism may involve the regulation of HSP47.
\end{abstract}

Correspondence to: Dr Yong Xie, Department of General Medicine, Chenzhou No. 1 People's Hospital, 102 Luojiajing Road, Chenzhou, Hunan 423000, P.R. China

E-mail: xieycs731@163.com

Key words: heat shock factor 1, myocardial fibrosis, type I collagen, type III collagen, heat shock protein 47 , insulin-like growth factor 1 , isoproterenol

\section{Introduction}

Myocardial fibrosis refers to excessive accumulation of collagen fibers in the heart that results from upregulated collagen fibers or altered components of collagen fibers in myocardial tissues, which is implicated in numerous physiological and pathological conditions (1-6). Although the precise mechanism remains elusive, one hypothesis is that the imbalance between the synthesis and degradation of myocardial collagen fibers leads to fibrosis in the heart $(5,6)$.

Numerous studies have shown that cytokines, including transforming growth factor (TGF), insulin-like growth factor (IGF) and fibroblast growth factor (FGF) have important roles in proliferation, extracellular matrix (ECM) deposition and organ fibrosis by interacting with the corresponding receptors (7-9). IGF-1 was found to protect against cardiac fibrosis in vivo, although it may promote fibrosis in other organs $(10,11)$.

The mouse model of isoproterenol (ISO)-induced myocardial fibrosis offers a tool for studying the functions of various genes. ISO is a synthetic non-selective $\beta$-adrenoceptor agonist whose subcutaneous injection induces heart failure and suppressed cardiac function due to myocardial hypertrophy and fibrosis $(11,12)$. The amplified inflammatory response after ISO injection is likely to be the cause of myocardial injury.

Heat shock proteins (HSPs) are protective proteins, which are present under normal conditions and are upregulated during stress (heat stress in particular). Being molecular chaperones, HSPs take part in protein folding, disaggregation, renaturing and transportation (13-15). HSPs are a superfamily of proteins, which are regulated by heat shock factor 1 (HSF1) $(16,17)$. They are classified into numerous sub-families according to their molecular weight, including HSP90, -70, -60 and small-molecular HSPs. HSP47 belongs to the small molecular family. As a molecular chaperone, HSP47 is involved in processing, folding, aggregation and secretion processes of collagen proteins in the endoplasmic reticulum, which has an important role in quality control of mature collagen, preventing generation and secretion of misfolded pro-collagen during stress (18). Thus, HSP47 may have an important role in the process of fibrosis in various organs. HSF1 is the main regulator of the HSP genes, 
suggesting it may also have an important role in the fibrotic process.

Although numerous studies have focused on the roles of HSF1 in liver (19-24), kidney or pulmonary fibrosis, there have been few studies on the role of HSF1 in experimentally induced myocardial fibrosis. In the present study, it was hypothesized that HSF1 has a promoting role in experimentally induced cardiac fibrosis, and the effect of HSF1 on ISO-induced myocardial fibrosis was investigated via histomorphological observation and determination of the expression of collagens and HSP47 as well as the activation of HSF1 itself in mice by using Kunming and HSF1 knockout mice (HSF1-/- mice).

\section{Materials and methods}

Materials. IGF-1 was purchased from PeproTech (Rocky Hill, NJ, USA). Anti-HSF1 (cat. no. SPA901) and anti-HSP47 (cat. no. SPA470) antibodies were from Stressgen (Enzo Life Sciences, Farmingdale, NY, USA). Anti-phospho HSF1 (ser307) (cat. no. ab47369), collagen (COL)-I (cat. no. ab6308) and COL-III (cat. no. ab82354) monoclonal antibodies were purchased from Abcam (Cambridge, UK). $\beta$-actin polyclonal antibody (cat. no. AF4000) was from R\&D Systems (Minneapolis, MN, USA), horseradish-peroxidase-labeled goat anti-rabbit, rabbit anti-goat immunoglobulin $\mathrm{G}$ antibodies and a diamminobenzidine (DAB) test kit were from Boster Biological Technology (Wuhan, China). Dulbecco's modified Eagle's medium (DMEM) and RPMI 1640 were from Gibco-BRL (Invitrogen Life Technologies, Carlsbad, CA, USA) and SDS, agarose, Hoechst 33258 and proteinase K were from Invitrogen Life Technologies. Acrylamide and $N, N^{\prime}$-methylene-bis-acrylamide were from Fluka (Sigma-Aldrich, St Louis, MO, USA). Dithiothreitol (DTT), ammonium persulfate, toluidine blue, tetramethylethylenediamine (TEMED) and an MTT kit were from Promega Corp. (Madison, WI, USA). Polyvinylidene difluoride (PVDF) membranes were purchased from Millipore (Billerica, MA, USA).

Adult Kunming mice (age, 7-8 weeks) were provided by the Animal Center of Central South University (Changsha, China). HSF1+/- and HSF-/- mice were kindly provided by Professor Ivor Benjamin (Division of Cardiology, University of Utah, Salt Lake City, UT, USA). The present study was approved by the ethics committee of Central South University.

\section{Methods}

Experimental groups and preparation of animal model. The Kunming mice were maintained at $25^{\circ} \mathrm{C}$, in an atmosphere containing $\sim 60 \%$ humidity, with free access to food and water. Kunming mice were randomly divided into three groups $(n=4 /$ group): i) Control: Kunming mice were injected subcutaneously with normal saline; ii) ISO group: ISO (Shanghai Harvest Pharmaceutical Co., Ltd., Shanghai, China) was subcutaneously injected beside the thoracic vertebrae of the mice at a dose of $40 \mathrm{mg} / \mathrm{kg}$ on the first day, $20 \mathrm{mg} / \mathrm{kg}$ on the second day, $10 \mathrm{mg} / \mathrm{kg}$ on the third day and $5 \mathrm{mg} / \mathrm{kg}$ on the fourth day. The dose $(5 \mathrm{mg} / \mathrm{kg})$ was then kept for 10 more days. iii) ISO + IGF-1 intervention group: After the mice were injected with ISO, IGF-1 $(2 \mu \mathrm{g} / \mathrm{kg})$ was immediately injected into the same location.
HSF-1 knockout mice were randomly divided into six groups: i) HSF-/- control; ii) ISO HSF-/- group; iii) ISO + IGF-1 HSF-/- group: iv) $\mathrm{HSF}-/+$ control; v) ISO HSF-/+ group; and vi) ISO + IGF-1 HSF-/+ group. The animal model was prepared as described in the corresponding groups of Kunming mice.

RNA extraction and reverse transcription quantitative polymerase chain reaction $(R T-q P C R)$. Cardiac tissue was ground in liquid nitrogen. Total RNA was extracted with TRIzol reagent (Invitrogen Life Technologies) according to the manufacturer's instructions. $1 \mu \mathrm{g}$ total RNA was reverse-transcribed by using a reverse transcription kit (Reverse Transcription system; Promega Corp.). For quantitative real-time PCR, a total of $100 \mathrm{ng}$ cDNA was used to assess HSP47 expression, whereas 10 ng cDNA was used for PCR of GAPDH as a control. The primer sequences were as follows: HSP47, forward 5'-TCACCACAGGATGGTGGACA-3' and reverse 5'-TGGTCAGCAGCTTCTCCAAG-3'; GAPDH, forward 5'-ACCA CAGTCCATGCCATCAC-3' and reverse 5'-TCCACCACCCTGTTG CTGTA-3' (SYBR Green I fluorescence dye was used to bind specifically to the minor groove of double-stranded DNA). The primers were chemically synthesized by Invitrogen Life Technologies (Shanghai, China). PCR was conducted using an Applied Biosystems 7500 Real-Time PCR system (Applied Biosystems Life Technologies, Foster City, CA, USA). The PCR mixture contained: $2 \mu \mathrm{l}$ cDNA, $0.2 \mu \mathrm{l}$ forward primer, $0.2 \mu 1$ reverse primer, $0.5 \mu 1$ 20X Quantifast SYBR ${ }^{\circledR}$ Green PCR kit (Qiagen, Hilden, Germany), $0.4 \mu \mathrm{l}$ dNTP $(2.5 \mathrm{mM}), 2.4 \mu \mathrm{l} \mathrm{\textrm {Mg } ^ { 2 + }}$ ( $25 \mathrm{mM}), 2 \mu \mathrm{l} 10 \mathrm{X}$ buffer, $0.2 \mu \mathrm{l}$ enzyme (5 units $/ \mu \mathrm{l})$, diluted to $20 \mu \mathrm{l}$ with $\mathrm{ddH}_{2} \mathrm{O}$. PCR cycling conditions were as follows: $\mathrm{HSP} 47,95^{\circ} \mathrm{C}$ for $2 \mathrm{~min}, 95^{\circ} \mathrm{C}$ for $10 \mathrm{sec}, 61^{\circ} \mathrm{C}$ for $10 \mathrm{sec}$ and $72^{\circ} \mathrm{C}$ for $45 \mathrm{sec}, 40$ cycles; GAPDH, $95^{\circ} \mathrm{C}$ for $2 \mathrm{~min}, 95^{\circ} \mathrm{C}$ for $10 \mathrm{sec}, 61^{\circ} \mathrm{C}$ for $10 \mathrm{sec}, 72^{\circ} \mathrm{C}$ for $45 \mathrm{sec}, 40$ cycles. All reactions followed the typical sigmoidal reaction profile, and the cycle threshold was used to measure amplicon abundance.

Protein extraction. Myocardial tissue was washed with Buffer A [20 mM 4-(2-hydroxyethyl)-1-piperazineethanesulfonic acid-KOH, $\mathrm{pH} 7.5 ; 10 \mathrm{mM} \mathrm{KCl} ; 1.5 \mathrm{mM} \mathrm{MgCl} 2 ; 1.0 \mathrm{mM}$ EDTA-Na; $1.0 \mathrm{mM}$ ethylene glycol tetraacetic acid-Na; $250 \mathrm{mM}$ sucrose] for $10 \mathrm{~min}$, subsequently homogenized on ice using a glass homogenizer and centrifuged at 100,000 x g for $30 \mathrm{~min}$ at $4^{\circ} \mathrm{C}$. The supernatant was pooled and protein concentrations were determined by the Bradford method (25), using Coomassie Brilliant Blue (Fluka). Protein samples were kept at $-80^{\circ} \mathrm{C}$ for future use.

Western blot analysis. Western blot analysis was performed as previously described (26). Briefly, $20 \mu \mathrm{g}$ protein was loaded in each lane. After SDS-PAGE, proteins were electrically transferred to a PVDF membrane. After blocking, primary antibodies $(1: 1,000)$ were added and incubated at room temperature for $1 \mathrm{~h}$. The primary antibodies used were as follows: Anti-COL-I , anti-COL-III, anti-phospho-HSF1, anti-HSP7, and anti- $\beta$-actin. After washing, secondary antibodies were added and incubated for about $45 \mathrm{~min}$. After thorough washing, the membrane was visualized with a DAB kit according to manufacturer's instructions. The blots were 


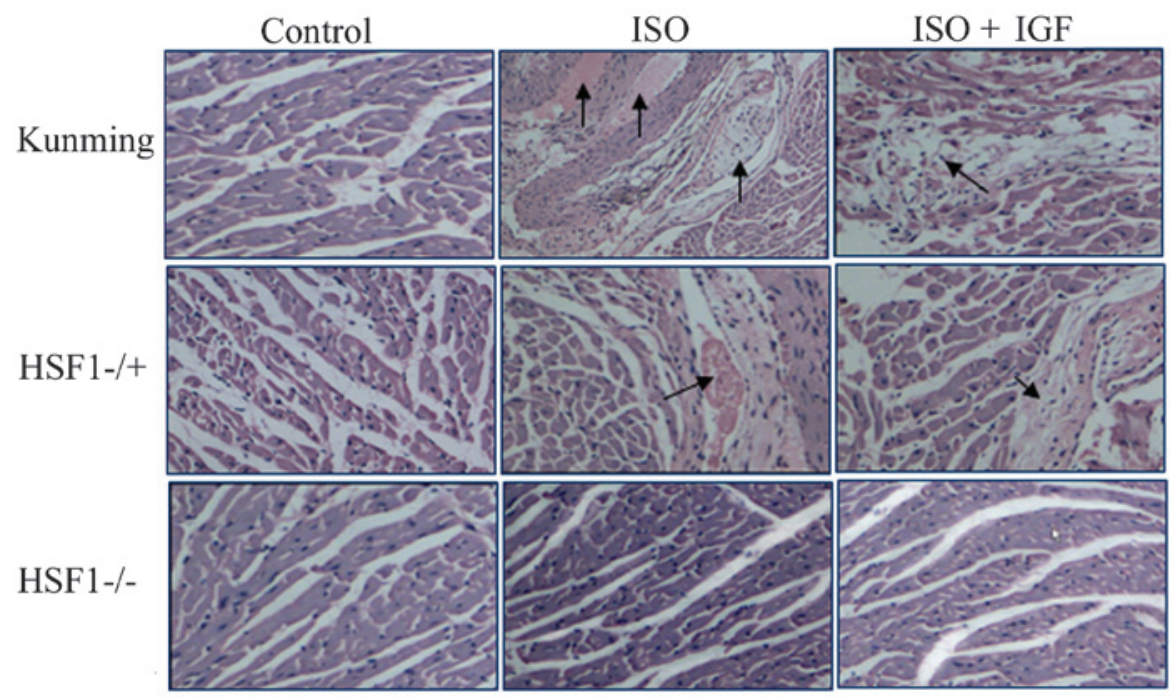

Figure 1. Effect of ISO and IGF-1 on myocardial fibrosis in Kunming, HSF1-/+ and HSF1-/- mice. After mice were injected with phosphate-buffered saline (control), ISO or ISO + IGF-1 for 14 days, hearts were fixed. Myocardial tissues were stained with hematoxylin and eosin in order to observe fibrosis in the heart. Arrows denote fibrosis. HSF, heat shock factor; ISO, isoproterenol; IGF, insulin-like growth factor 1.

A

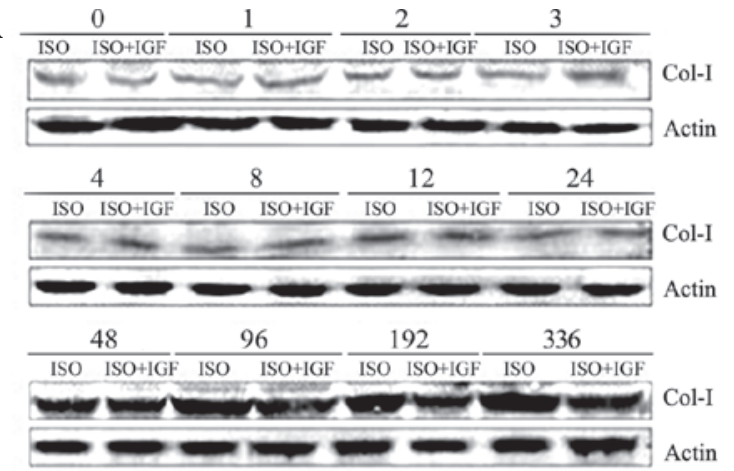

C

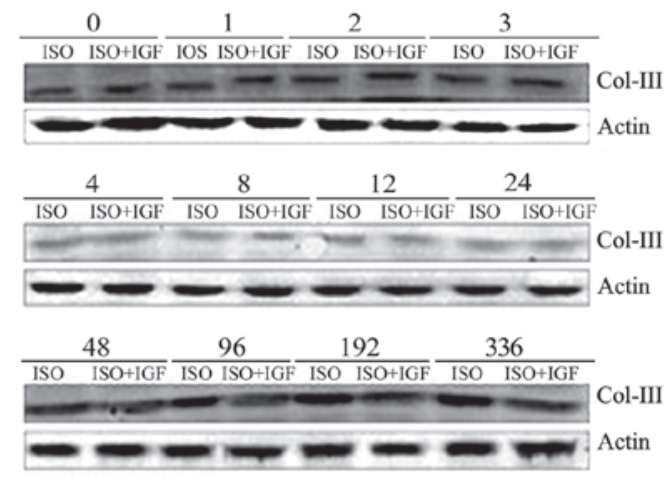

B

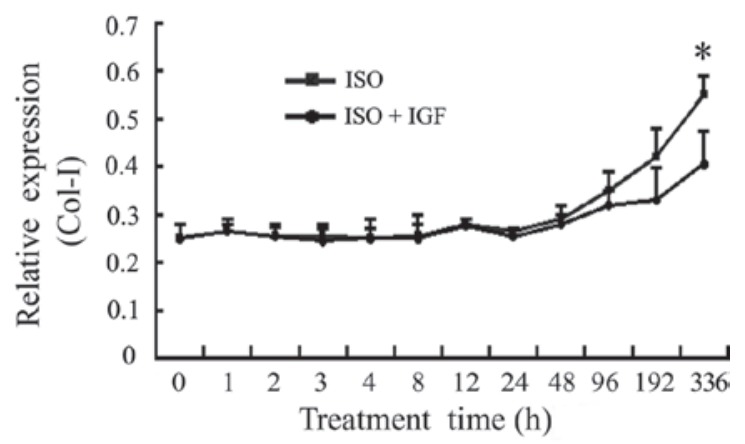

D

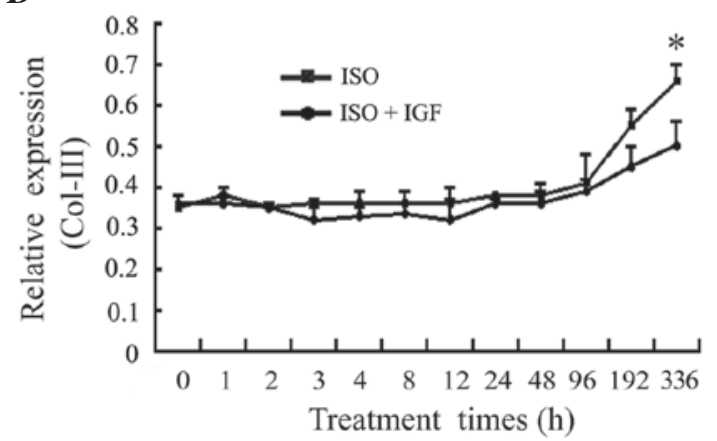

Figure 2. ISO induces the protein expression of type I and III collagen in Kunming mice. (A) After the mice were injected with ISO or ISO + IGF-1 for the indicated times, total proteins of the heart were extracted and subjected to western blot analysis for type I collagen protein. A representative western blot of three different experiments is shown. (B) Semi-quantitative analysis of type I collagen protein bands against $\beta$-actin $(n=3)$. (C) The mice were injected with ISO or ISO + IGF-1, and total proteins were extracted and subjected to western blot analysis for type III collagen protein. A representative western blot of three different experiments is shown. (D) Semi-quantitative analysis of type III collagen protein bands against $\beta$-actin (n=3). Values are expressed as the mean \pm standard error of the mean. ${ }^{*} \mathrm{P}<0.05$ vs. ISO + IGF-1. ISO, isoproterenol; IGF, insulin-like growth factor 1; Col, collagen.

analyzed using Bandleader 3.0 (Magnitec Ltd., Tel Aviv, Israel).

Histochemistry. For histological analysis, hearts were fixed by perfusion with $10 \%$ formalin. Fixed hearts were embedded in paraffin and sectioned $(4 \mu \mathrm{m})$. The myocyte cross-sectional diameter was measured in the sections stained with hematoxylin and eosin, and suitable cross-sections were defined as having nearly circular capillary profiles and nuclei $(n=100$ in each group).

Statistical analysis. Values are expressed as the mean \pm standard error of the mean. Multiple group comparison was performed by one-way analysis of variance (ANOVA), followed by the 
A

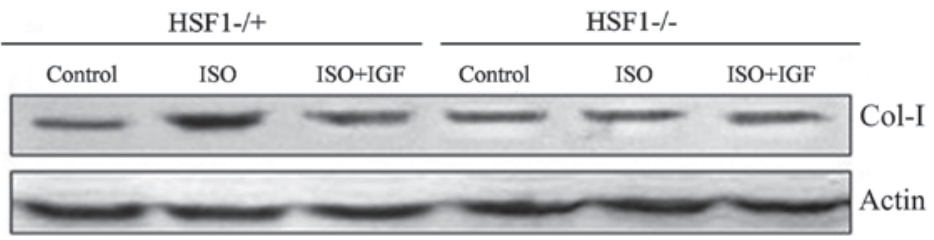

B

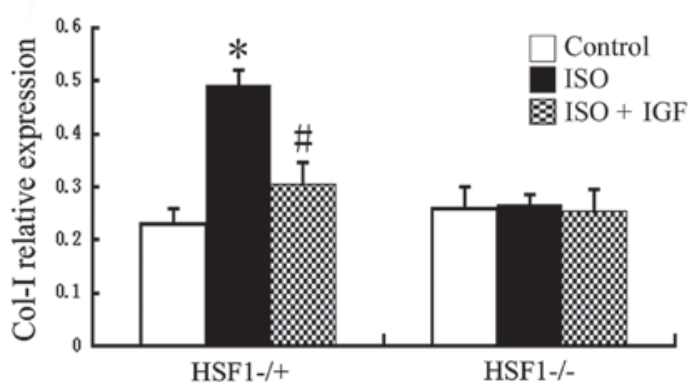

Figure 3. ISO-induced expression of type I collagen protein is dependent on HSF1 in mice. (A) HSF1-/+ or HSF1-/- mice were injected with phosphate-buffered saline (control), ISO or ISO + IGF-1 for 14 days, and total proteins of the heart were extracted and subjected to western blot analysis for type I collagen protein. Shown is a representative western blot of three independent experiments. (B) Semi-quantitative analysis of type I collagen protein bands against $\beta$-actin $(\mathrm{n}=3)$. Values are expressed as the mean \pm standard error of the mean. ${ }^{*} \mathrm{P}<0.05$ vs. control; ${ }^{*} \mathrm{P}<0.05$ vs. ISO. HSF, heat shock factor; ISO, isoproterenol; IGF, insulin-like growth factor 1 .

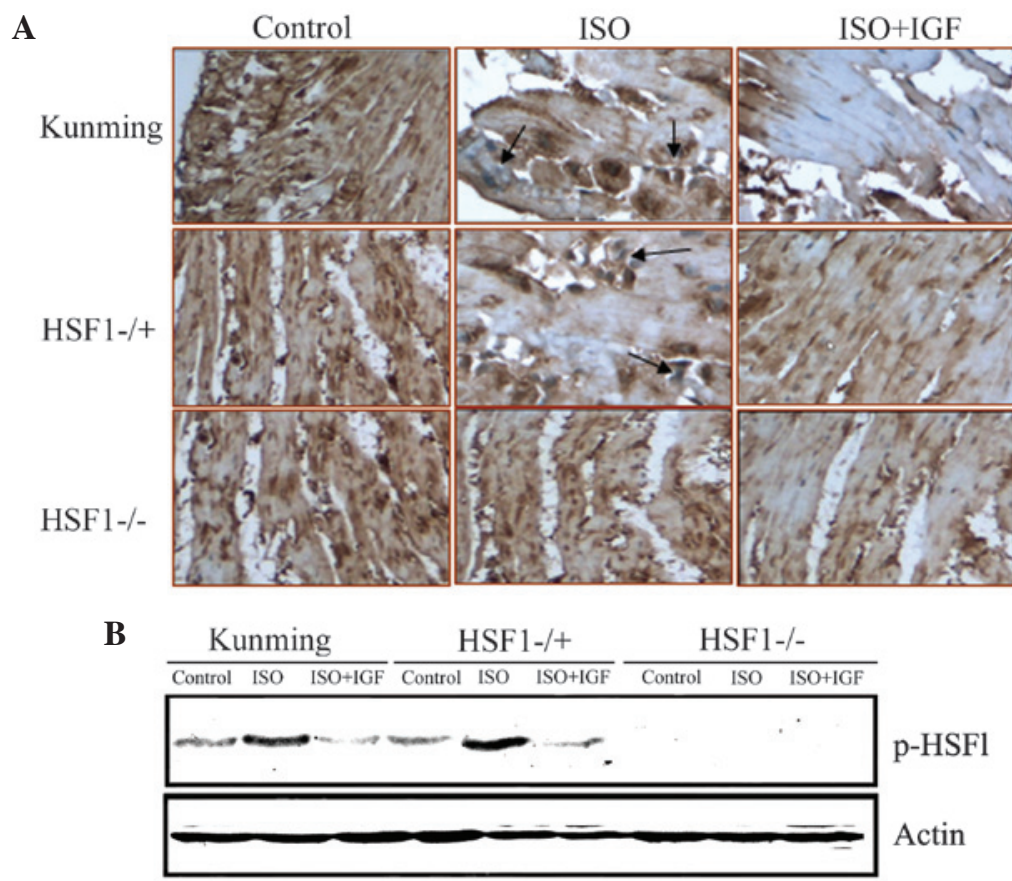

Figure 4. ISO induces HSF1 activation. (A) After Kunming, HSF1-/+ and HSF1-/- mice were injected with phosphate-buffered saline (control), ISO or ISO + IGF-1 for 14 days, HSF1 protein in the cardiomyocytes was stained with a fluorescence-labeled antibody and assessed under a fluorescent microscope. Arrows denote an increase in nuclear HSF1 protein. (B) Mice were treated as in A, and total proteins were extracted and subjected to SDS-PAGE followed by immunoblotting using an anti-phospho-HSF1 (Ser307) antibody. $\beta$-actin was used as an internal control. p-HSF, phosphorylated heat shock factor; ISO, isoproterenol; IGF, insulin-like growth factor 1.

Bonferroni procedure for comparison of means. Comparison between two groups were analyzed by the tow-tailed Student's t-test or two-way ANOVA. P $<0.05$ was considered to indicate a statistically significant difference between values.

\section{Results}

HSF1 is required for the establishment of an ISO-induced mouse model of myocardial fibrosis. To observe the effects of HSF1 on cardiac fibrosis, a myocardial fibrosis model was prepared using HSF-/+ mice. After injection of ISO for 8 or 14 days, a large number of fibres were found to accumulate between cardiomyocytes or around aortic ventricles of the heart in Kunming mice, and this accumulation was significantly inhibited by intervention with IGF-1, and similar results were observed in $\mathrm{HSF}-/+$ mice treated with ISO (Fig. 1), indicating that myocardial fibrosis was induced by ISO but reversed by IGF-1 treatment, in accordance to other 
A

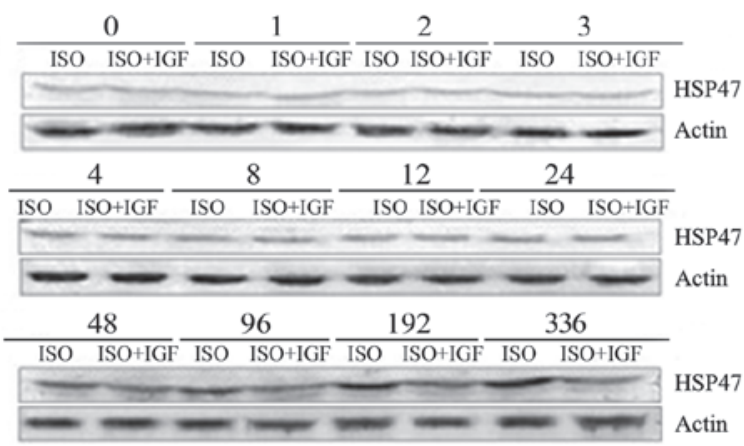

C

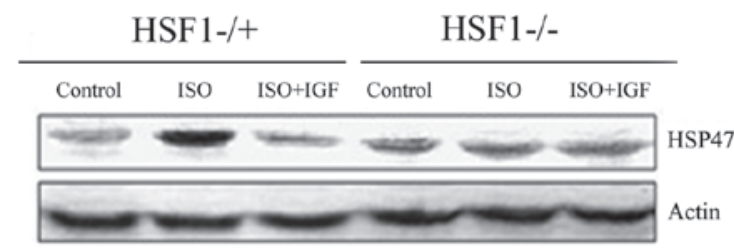

B
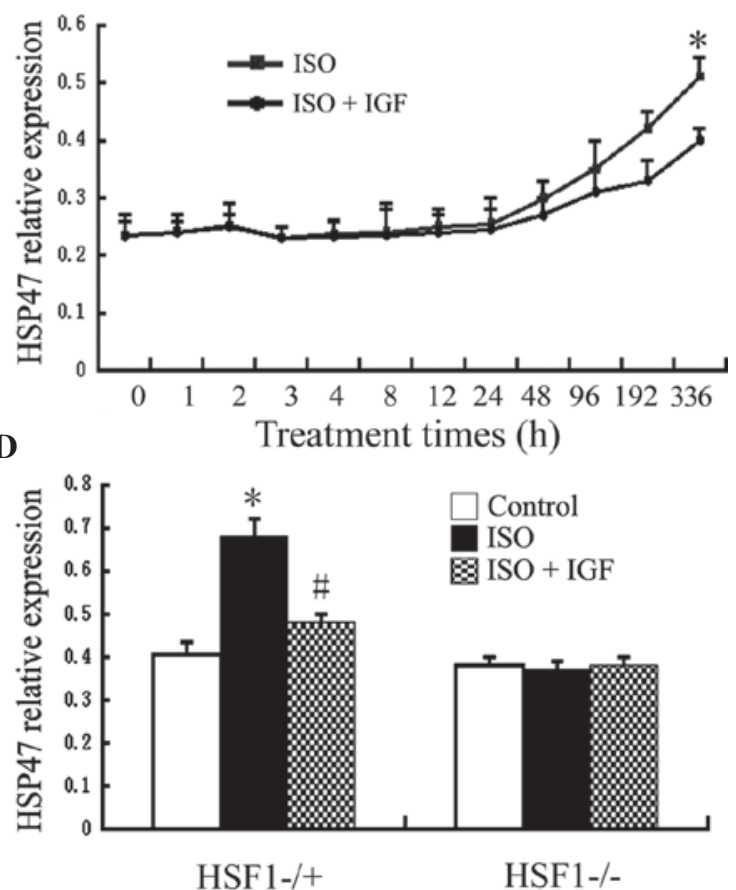

Figure 5. ISO-induced expression of HSP47 is dependent on HSF1. (A) Kunming mice were injected with phosphate-buffered saline (control), ISO or ISO + IGF-1 for the indicated times, and total proteins of the heart were extracted and subjected to western blot analysis for HSP47 protein. Shown is a representative western blot of three independent experiments. (B) Semi-quantitative analysis of HSP47 protein bands against $\beta$-actin ( $\mathrm{n}=3$ ). ${ }^{*} \mathrm{P}<0.05 \mathrm{vs}$. ISO $+\mathrm{IGF}-1$. (C) HSF1-/+ or HSF1-/- mice were injected with ISO or ISO + IGF-1 for 14 days, and total proteins of the heart were extracted and subjected to western blot analysis for HSP47 protein. Shown is a representative western blot of three independent experiments. (D) Semi-quantitative analysis of HSP47 protein bands against $\beta$-actin $(n=3)$. Values are expressed as the mean \pm standard error of the mean. ${ }^{*} \mathrm{P}<0.05$ vs. control; ${ }^{\#} \mathrm{P}<0.05$ vs. ISO. HSF, heat shock factor; ISO, isoproterenol; IGF, insulin-like growth factor 1; HSP, heat shock protein.

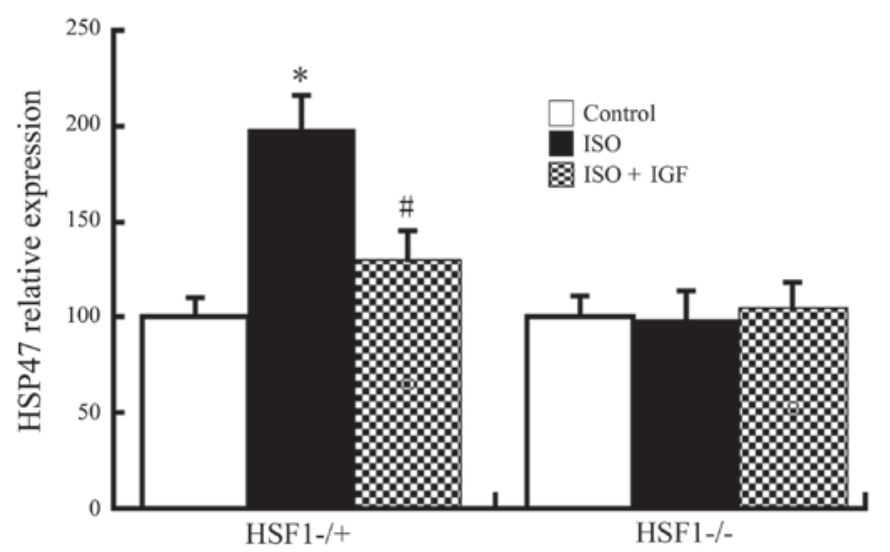

Figure 6. ISO induces HSP47 transcription. HSF1-/+ or HSF1-/- mice were injected with phosphate-buffered saline (control), ISO or ISO + IGF-1 as indicated for 14 days, and total RNA was extracted. Reverse transcription quantitative polymerase chain reaction analysis was performed to measure HSP47 mRNA levels, and HSP47 mRNA was normalized to GAPDH (n=3). Values are expressed as the mean \pm standard error of the mean. ${ }^{*} \mathrm{P}<0.05$ vs. control; "P<0.05 vs. ISO. HSF, heat shock factor; ISO, isoproterenol; IGF, insulin-like growth factor 1; HSP, heat shock protein.

studies $(27,28)$. By contrast, in HSF1-/- mice, cardiac fibrosis was not found to be induced by ISO (Fig. 1). These results suggested that HSF1 is required for myocardial fibrosis in mice, at least that induced by ISO.

HSF1 is required for the expression of myocardial collagen proteins induced by ISO. Though disease processes and origins may differ, excess deposition of fibrillar collagens type I and III characterizes fibrosis in the heart (29). To investigate the effect of HSF1 on the protein expression of western blot analysis was performed. As shown in Fig. 2, the protein expression of collagen type I and III only began to increase after 8 days, and was significantly upregulated after 14 days of ISO injection. However, IGF-1 treatment inhibited the upregulation of the protein expression of collagen type I and III. In HSF-/+ mice, the effect of ISO was similar to that in Kunming mice (Fig. 3). By contrast, in HSF-/- mice, the expression of collagen proteins (types I and III) was not found to significantly alter, even after 14 days of ISO injection (Fig. 3). These results suggested that HSF1 is required for expression of myocardial collagen proteins (type I and III) induced by ISO in mice.

ISO mediates HSFl protein activation. The above results demonstrated that HSF1 is required for myocardial fibrosis and collagen protein expression induced by ISO in mice. As HSF1 is a transcription factor, the present study hypothesized that ISO-induced expression of collagen proteins is directly or indirectly dependent on the transcriptional functions of HSF1. To test this hypothesis, HSF1 activation was first examined by immunohistochemistry. As shown in Fig. 4A, HSF1 protein expression in the nuclei of cardiac cells from Kunming mice and HSF1-/ + mice after treatment with ISO for 14 days was significantly increased, but this induced increase in nuclear HSF1 protein was inhibited by IGF-1 (Fig. 4A). 
The activation of HSF1 protein involves its phosphorylation, which leads to its nuclear tanslocation. To further investigate whether HSF1 activation is induced by ISO, phosphorylated HSF1 ( $\mathrm{p}-\mathrm{HSF} 1$ ) was detected using western blot analysis. As shown in Fig. 4B, ISO treatment induced an increase in p-HSF1 in Kunming as well as in HSF1-/+ mice. The results suggested that HSF1 activation is required for ISO-induced myocardial fibrosis in mice.

HSP47 upregulation induced by ISO is dependent on HSFI and correlates with that of collagen proteins. HSF1 regulates expression of HSPs. Among HSPs, HSP47 is closely associated with fibrosis (18). Therefore, the present study investigated the expression of HSP47 in mouse models of myocardial fibrosis induced by ISO. As shown in Fig. 5, in Kunming mice, HSP47 protein expression was induced after $96 \mathrm{~h}$ of ISO injection and was markedly increased after injection for $336 \mathrm{~h}$, while IGF-1 treatment inhibited this induced expression (Fig. 5A and B), which correlates with upregulation of collagen I and III. Similarly, after treatment with ISO for $336 \mathrm{~h}, \mathrm{HSP} 47$ protein expression was markedly increased in HSF1-/+ mice, while this increase was inhibited by IGF-1 intervention (Fig. 5C and D). However, HSP47 expression was not induced by ISO treatment in HSF1-/- mice, even after $336 \mathrm{~h}$ (Fig. 5). These results suggested that HSF1 is required for HSP47 expression induced by ISO.

In order to investigate whether the increase in HSP47 protein is dependent on its transcription, HSP47 RNA was examined by RT-qPCR. As shown in Fig. 6, in Kunming and HSF1-/+ mice, treatment with ISO induced an increase in HSP47 mRNA levels, which was inhibited by IGF-1, but ISO did not induce any increases in HSP47 mRNA in HSF1-/- mice, which was consistent with the effects observed regarding protein expression. All of these results indicated that ISO induces HSP47 expression, possibly through HSF1-mediated increases in its transcription.

\section{Discussion}

It is well known that continuous use of $\beta$-agonist ISO causes myocardial hypertrophy and myocardial fibrosis in rats, which may be due to cardiac hypertrophy and the activation of fibrosis-associated signaling pathways, including mitogen-activated protein kinase, c-Jun N-terminal kinase/signal transducer and activator of transcription and nuclear factor $\kappa \mathrm{B}$ by ISO $(30,31)$. In the present study, it was demonstrated that subcutaneous injection of ISO in Kunming mice and HSF1-/+ mice caused myocardial hypertrophy, leading to severe fibrosis, accompanied by a significant increase in the expression of collagen type I and III, indicating that the animal model of myocardial fibrosis was successfully established, consistent with other studies (27,32-34). Of note, subcutaneous injection of ISO did not cause any myocardial fibrosis in HSF1-/- mice, indicating that HSF1 is required for myocardial fibrosis in mice, at least in the mouse model induced by ISO. As a transcription factor activated HSF1 regulates the expression of other genes $(35,36)$. Immunohistochemical analysis showed that, in Kunming and HSF1-/ + mice, ISO induced large amounts of HSF1 protein in cardiac nuclei, indicating that it may function as a transcription factor in the process of cardiac fibrosis.
As a transcription factor, HSF1 mainly regulates the expression of HSPs. Among the known HSPs, HSP47 is most closely associated with myocardial fibrosis. Therefore, the present study assessed the possibility of HSF1 regulating the expression of HSP47. It was found that in Kunming and HSF1-/+ mice, ISO induced myocardial fibrosis, accompanied with HSP47 upregulation. However, the use of ISO did not induce myocardial fibrosis in HSF1-/- mice, nor did it increase in HSP47 expression, suggesting that HSP47 upregulation is regulated by HSF1. Bioinformatics analysis further showed that the HSP47 promoter region contains HSF1 binding sites. Therefore, HSF1 directly regulates the expression of HSP47 in this model.

In the present study, the role of IGF-1 in cardiac fibrosis was also examined. The results showed that IGF-1 inhibited ISO-induced myocardial fibrosis and also inhibited HSP47 expression and activation of HSF1. Taking into account the regulation of the expression of HSP47 by HSF1 and the inhibition of fibrosis and HSP47 expression in HSF1-/- mice, it was speculated that IGF-1 downregulates HSP47 expression by inhibiting the activation of HSF1, and that HSP47 may affect the synthesis of collagen protein; however, the detailed underlying molecular mechanisms remain to be elucidated.

In conclusion, the present study successfully induced myocardial fibrosis in mice through treatment with ISO. It was demonstrated that HSF1 is required for myocardial fibrosis in this animal model. As myocardial fibrosis was accompanied by elevated HSP47 levels, it was suggested that HSP47 may have an important role in myocardial fibrosis. The exact underlying molecular mechanisms remain to be elucidated in future studies.

\section{Acknowledgements}

The authors of the present study are grateful to Professor Xianzhong Xiao (Central South University, Changsha, China) for providing good conditions for this study.

\section{References}

1. Ghosh AK, Bradham WS, Gleaves LA, De Taeye B, Murphy SB, Covington JW and Vaughan DE: Genetic deficiency of plasminogen activator inhibitor-1 promotes cardiac fibrosis in aged mice: Involvement of constitutive transforming growth factor-beta signaling and endothelial-to-mesenchymal transition. Circulation 122: 1200-1209, 2010.

2. Krieg T, Abraham D and Lafyatis R: Fibrosis in connective tissue disease: The role of the myofibroblast and fibroblast-epithelial cell interactions. Arthritis Res Ther 9 (Suppl 2): S4, 2007.

3. Kwak HB, Kim JH, Joshi K, Yeh A, Martinez DA and Lawler JM: Exercise training reduces fibrosis and matrix metalloproteinase dysregulation in the aging rat heart. FASEB J 25: 1106-1117, 2011.

4. Yu XY, Qiao SB, Guan HS, Liu SW and Meng XM: Effects of visfatin on proliferation and collagen synthesis in rat cardiac fibroblasts. Horm Metab Res 42: 507-513, 2010.

5. Rezzani R, Angoscini P, Rodella L and Bianchi R: Alterations induced by cyclosporine $\mathrm{A}$ in myocardial fibers and extracellular matrix in rat. Histol Histopathol 17: 761-766, 2002.

6. Gao HC, Zhao H, Zhang WQ, Li YQ and Ren LQ: The role of the Rho/Rock signaling pathway in the pathogenesis of acute ischemic myocardial fibrosis in rat models. Exp Ther Med 5: 1123-1128, 2013.

7. Díez J: Mechanisms of cardiac fibrosis in hypertension. J Clin Hypertens (Greenwich) 9: 546-550, 2007.

8. Hinz B: Formation and function of the myofibroblast during tissue repair. J Invest Dermatol 127: 526-537, 2007. 
9. Sato M, Shegogue D, Gore EA, Smith EA, McDermott PJ and Trojanowska M: Role of p38 MAPK in transforming growth factor beta stimulation of collagen production by scleroderma and healthy dermal fibroblasts. J Invest Dermatol 118: 704-711, 2002.

10. Bhattacharyya S, Wei J and Varga J: Understanding fibrosis in systemic sclerosis: Shifting paradigms, emerging opportunities Nat Rev Rheumatol 8: 42-54, 2012.

11. Huynh K, McMullen JR, Julius TL, Tan JW, Love JE, Cemerlang N, Kiriazis H, Du XJ and Ritchie RH: Cardiac-specific IGF-1 receptor transgenic expression protects against cardiac fibrosis and diastolic dysfunction in a mouse model of diabetic cardiomyopathy. Diabetes 59: 1512-1520, 2010.

12. Haleagrahara N, Chakravarthi S and Mathews L: Insulin like growth factor-1 (IGF-1) causes overproduction of IL-8, an angiogenic cytokine and stimulates neovascularization in isoproterenol-induced myocardial infarction in rats. Int $\mathbf{J}$ Mol Sci 12: 8562-8574, 2011

13. Yousefi K, Fathiazad F, Soraya H, Rameshrad M, MalekiDizaji N and Garjani A: Marrubium vulgare L. methanolic extract inhibits inflammatory response and prevents cardiomyocyte fibrosis in isoproterenol-induced acute myocardial infarction in rats. Bioimpacts 4: 21-27, 2014.

14. Xiao X and Benjamin IJ: Stress-response proteins in cardiovascular disease. Am J Hum Genet 64: 685-690, 1999.

15. Benjamin IJ and McMillan DR: Stress (heat shock) proteins: Molecular chaperones in cardiovascular biology and disease. Circ Res 83: 117-132, 1998.

16. Kregel KC: Heat shock proteins: Modifying factors in physiological stress responses and acquired thermotolerance. J Appl Physiol 1985 92: 2177-2186, 2002.

17. Hengartner MO: The biochemistry of apoptosis. Nature 407: 770-776, 2000

18. Bellaye PS, Burgy O, Causse S, Garrido C and Bonniaud P: Heat shock proteins in fibrosis and wound healing: Good or evil? Pharmacol Ther 143: 119-132, 2014.

19. Park SJ, Sohn HY and Park SI: TRAIL regulates collagen production through HSF1-dependent Hsp47 expression in activated hepatic stellate cells. Cell Signal 25: 1635-1643, 2013

20. Tang Y and Zheng J: Roles of HSP47/HSF1 in pulmonary fibrosis. Shandong Yi Yao 50: 117-118, 2010 (In Chinese).

21. Xiao H, Lv J, Chen Q, Liu R and Ling G: Role of HSP47 in renal tubulointerstitial fibrosis induced by transforming growth factor $\beta 1$. Chin J Nephrol 27: 923-927, 2011 (In Chinese).

22. Deng J, Wang D, Zhang Y and Yuan F: The expression of HSP47 in renal tissues of chronic renal disease patients and its significance. Chongqing Yi Xue 34: 1029-1031, 2005 (In Chinese).
23. Hai G, Li J, Jia Y, Xia W, Chen Y and Liu J: The effect of TGF- $\beta 1$ on the expression of HSP47 and collagen in HFL cells. Guangdong Yi Xue 34: 2632-2634, 2013 (In Chinese).

24. Li Y, Wu W, Jiang Y and Wang K: Effect of heat shock protein 47 on the expression of collagen I induced by TGF-beta(1) in hepatic stellate cell-T6 cells. Zhong Nan Da Xue Xue Bao Yi Xue Ban 32: 650-655, 2007 (In Chinese).

25. Bradford MM: A rapid and sensitive method for the quanititation of microgram quantities of protein utilizing the principle of protein-dye binding. Anal Biochem 72: 248-254, 1976.

26. Nagata K: Hsp47: A collagen-specific molecular chaperone. Trends Biochem Sci 21: 22-26, 1996.

27. Siu PM, Wang Y and Alway SE: Apoptotic signaling induced by $\mathrm{H} 2 \mathrm{O} 2$-mediated oxidative stress in differentiated $\mathrm{C} 2 \mathrm{C} 12$ myotubes. Life Sci 84: 468-481, 2009.

28. Dong RQ, Wang ZF, Zhao C, Gu HR, Hu ZW, Xie J and Wu YQ: Toll-like receptor 4 knockout protects against isoproterenol-induced cardiac fibrosis: The role of autophagy. J Cardiovasc Pharmacol Ther 20: 84-92, 2015.

29. Hribal ML, Procopio T, Petta S, Sciacqua A, Grimaudo S, Pipitone RM, Perticone F and Sesti G: Insulin-like growth factor-I, inflammatory proteins, and fibrosis in subjects with nonalcoholic fatty liver disease. J Clin Endocrinol Metab 98: E304-E308, 2013.

30. Roche P and Czubryt MP: Transcriptional control of collagen I gene expression. Cardiovasc Hematol Disord Drug Targets 14: 107-120, 2014.

31. Ocaranza MP, Díaz-Araya G, Chiong M, Muñoz D, Riveros JP, Ebensperger R, Sabat S, Irarrázaval P, Jalil JE and Lavandero S: Isoproterenol and angiotensin I-converting enzyme in lung, left ventricle, and plasma during myocardial hypertrophy and fibrosis. J Cardiovasc Pharmacol 40: 246-254, 2002.

32. Takemoto Y, Yoshiyama M, Takeuchi K, Omura T, Komatsu R, Izumi Y, Kim S and Yoshikawa J: Increased JNK, AP-1 and NF-kappa B DNA binding activities in isoproterenol-induced cardiac remodeling. J Mol Cell Cardiol 31: 2017-2030, 1999.

33. Gallego M, Espiña L, Vegas L, Echevarria E, Iriarte MM and Casis O: Spironolactone and captopril attenuates isoproterenol-induced cardiac remodelling in rats. Pharmacol Res 44: 311-315, 2001.

34. Leenen FH, White R and Yuan B: Isoproterenol-induced cardiac hypertrophy: Role of circulatory versus cardiac renin-angiotensin system. Am J Physiol Heart Circ Physiol 281: H2410-H2416, 2001.

35. Ciocca DR, Arrigo AP and Calderwood SK: Heat shock proteins and heat shock factor 1 in carcinogenesis and tumor development: an update. Arch Toxicol 87: 19-48, 2013.

36. Vihervaara A and Sistonen L: HSF1 at a glance. J Cell Sci 127: 261-266, 2014. 